\title{
Primary Hypothyroidism Presenting as Growth Delay and Pituitary Enlargement
}

\author{
John D. Farley, Ellen L. Toth and Edmond A. Ryan
}

\begin{abstract}
We report the case of a young boy being considered for pituitary surgery because of pituitary enlargement found during assessment of growth delay. There was no goitre but he was hypothyroid clinically and biochemically. The finding of an elevated TSH suggested primary thyroid disease with thyrotroph hyperplasia. Treatment with L-thyroxine resulted in prompt resolution of his pituitary enlargement and improvement in his visual fields.
\end{abstract}

\begin{abstract}
RÉSUMÉ: Hypothyrödie primaire se manifestant par un retard de croissance et une hypertrophie pituitaire. Nous présentons le cas d'un jeune garçon chez qui une chirurgie de l'hypophyse fut considérée en raison d'un élargissement de cette glande remarqué lors de l'évaluation d'un retard de croissance. Même s'il était hypothyroïdien cliniquement et biochimiquement, il ne présentait cependant pas de goïtre. Une élévation de la TSH suggérait une maladie thyroïdienne primaire avec hyperplasie thyrotrope. Le traitement par la L-thyroxine a provoqué une résolution rapide de son hypertrophie pituitaire et une amélioration de ses champs visuels.
\end{abstract}

Can. J. Neurol. Sci. 1988; 15:35-37

Pituitary hyperplasia as a consequence of primary hypothyroidism first reported in $1851^{\prime}$ remains an infrequently recognized phenomenom. There are reports of misdiagnoses and even pituitary irradiation ${ }^{2}$ or surgery ${ }^{3,4}$ for this condition. Secondary hyperplasia of the thyrotrophs may result in suprasellar enlargement and may manifest as visual field defects. ${ }^{3.5}$ Once considered, the diagnosis of primary hypothyroidism is easily established and the outcome of treatment is usually gratifying. We report a case of a young boy who presented with growth delay and pituitary enlargement secondary to primary hypothyroidism who showed rapid resolution once appropriate treatment was instituted.

\section{Case Report}

A 12-year-old boy was referred to the Endocrinology service of the University of Alberta Hospital for the assessment of a pituitary tumor. He first came to medical attention as a result of abnormal bone growth noted on dental X-rays ordered after a routine dental examination. $X$-rays of the hands showed delayed bone growth and the skull X-rays revealed an enlarged sella turcica.

His development was normal until the age of ten but since then he had not gained any weight or height. Iron supplements had been prescribed for a borderline anemia. His activity level was thought to be normal. Early developmental milestones were normal and he did well at school. He was somewhat intolerant of the cold and the skin was noted to be dry. Headache, visual disturbances, decreased appetite and constipation were all denied. There was no family history of endocrine disorders. Except for iron supplements he was on no other medications.

On examination he was alert. His height was $120.4 \mathrm{cms}$ and weight $26.6 \mathrm{~kg}$ both well below the 5 th percentile. He had marked pallor and a carotene tinge to his skin. The pulse rate was 82 beats per minute and the B.P. $100 / 60 \mathrm{mmHg}$ with no postural change. Examination of the head and neck, including fundi, was normal. Visual fields appeared normal to confrontation. The thyrojd gland was just palpable lying very low in the sternal notch and was smooth and firm. There was no lymphadenopathy. The heart, lungs and abdomen were normal. He was prepubertal. On neurological examination, his ankle jerk relaxation phase was markedly delayed.

The initial hemoglobin was $9.4 \mathrm{~g} / \mathrm{dl}$ with a normocytic normochromic smear. The relative reticulocyte count was 0.027 (normal $0.02-0.20$ ). The absolute count was $845 \times 10^{8} / \mathrm{L}$ (normal $200-600 \times 10^{8} / \mathrm{L}$ ). The white cell count, B 12 and folate were normal. Serum electrolytes and a biochemical survey were normal.

Thyroid function studies revealed: T4 RIA of $15 \mathrm{nmol} / \mathrm{L}$ (normal 70 160 ), free T4 index of 12 (normal $60-150$ ) and a T3 RIA of $1.8 \mathrm{nmol} / \mathrm{L}$ (normal 1.8 -3.3). The thyroid stimulating hormone (TSH) was 38.6 and $49.5 \mathrm{mIU} / \mathrm{L}$ on two occasions (normal 0 - 5.6). Thyroid antibodies were positive for thyroglobulin antibody at a dilution of $1 / 80$ and $1 / 1600$ for the microsomal antibody. The prolactin level was $45.5 \mathrm{ug} / \mathrm{L}$ (normal 5 . 25), LH 7.3 IU/L (normal $4.0-23.0$ ) and FSH 8.8 IU/L (normal 9.5 - 
16.0). Post metapyrone, the 11-deoxycortisone rose appropriately to $522 \mathrm{nmol} / \mathrm{L}$. The insulin tolerance test revealed a satisfactory increment of cortisol from $499 \mathrm{nmol} / \mathrm{L}$ to $712 \mathrm{nmol} / \mathrm{L}$ in one hour. Simultaneous growth hormone $(\mathrm{GH})$ determinations also peaked from a baseline of $0.9 \mathrm{ug} / \mathrm{L}$ to $6.6 \mathrm{ug} / \mathrm{L}$.

Computerized Tomography (CT) scan demonstrated a large enhancing pituitary mass with suprasellar extension (Figure 1A). There were no calcifications or cystic areas. Visual field studies showed an upper field cut (Figure 2).

\section{Course}

He was started on $0.025 \mathrm{mg}$ of L-Thyroxine and this was subsequently increased to $0.05 \mathrm{mg}$ in two weeks. Six weeks after starting therapy he felt much better and was more active at home. Repeat visual field examination showed improvement (Figure 2). A repeat scan showed a significant decrease in size of the pituitary gland (Figure 1B). The free T4 index was normal and the TSH 8.6; the repeat hemoglobin was unchanged but the relative reticulocyte count had risen to 0.064 .

\section{Discussion}

Pituitary enlargement caused by primary hypothyroidism is not frequently recognized clinically, although it is commonly found at autopsy of patients with a history of myxedema ${ }^{6}$ Primary hypothyroidism frequently presents as growth delay, but has been reported as mimicking pituitary tumor both in children ${ }^{2,7}$ and in adults. ${ }^{3 \cdot 5,8,9}$

Our patient was first noted to have delayed bone growth on $\mathrm{X}$-rays taken by his dentist. Subsequently he was referred for evaluation of a pituitary mass lesion. He was markedly hypothyroid both clinically and biochemically though without a goitre. His TSH, although not as high as some other reports in the literature, was clearly elevated. The importance of measuring the TSH in this setting must be stressed, otherwise he would likely have been submitted to unnecessary surgery as previously reported. ${ }^{3,4}$ The absence of a goitre should not rule out the possibility of primary hypothyroidism. ${ }^{2.8}$ The positive thy. roid antibodies further substantiated primary hypothyroidism in our patient and were indicative of Hashimoto's thyroiditis. Except for the elevated prolactin, a common finding in hypothyroidism, ${ }^{10}$ the remainder of his pituitary function testing was normal. This was unlike patients reported ${ }^{8.16}$ who manifested abnormal GH responses to insulin-induced hypoglycemia or

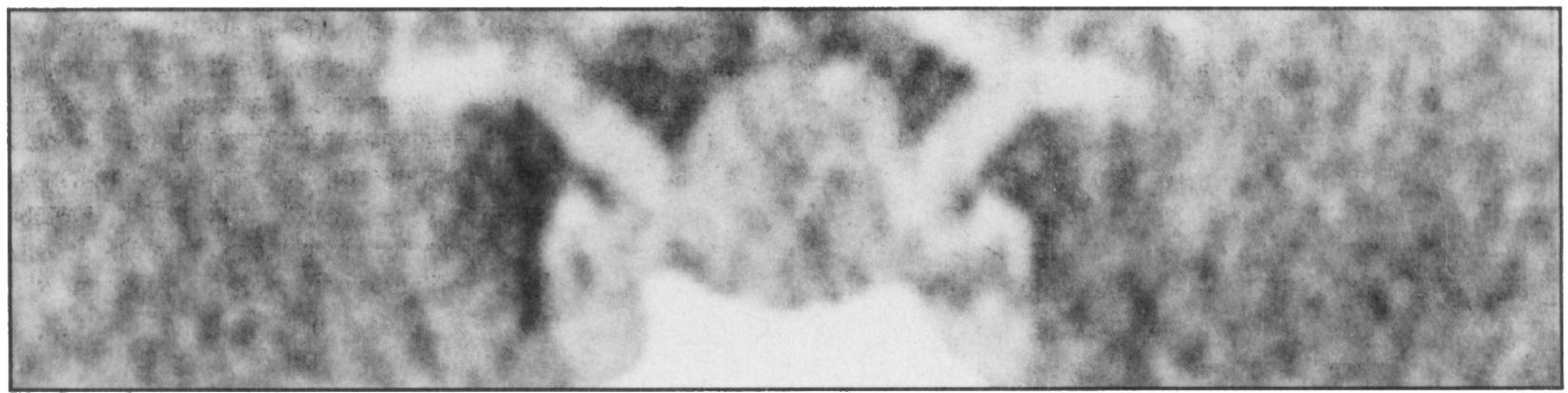

A

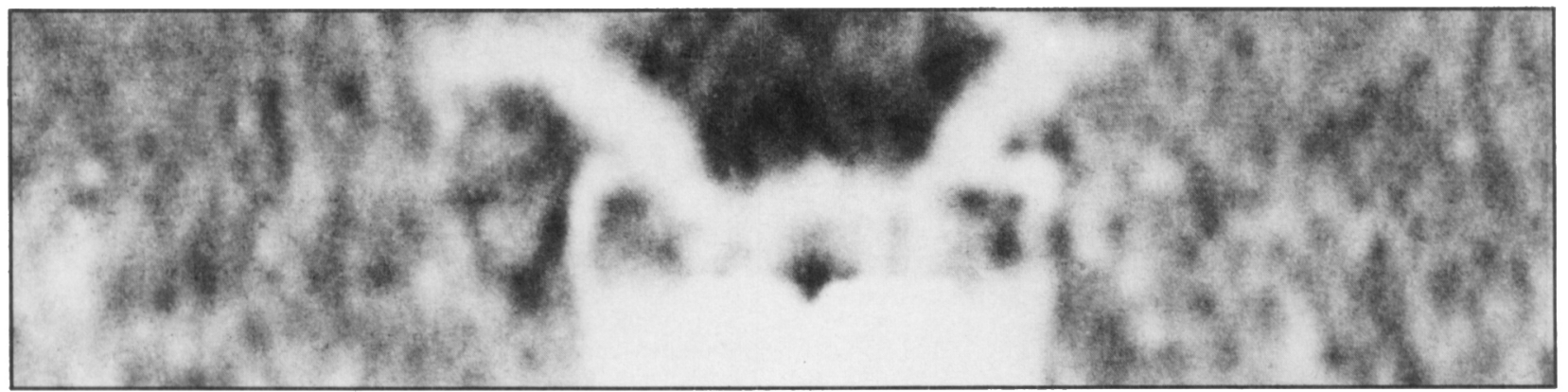

B

Figure I(A) - CT scan of pituitary showing a large pituitary "tumor" with suprasellar extension. (B) - CT scan of pituitary taken after 6 weeks of thyroxine therapy showing resolution of pituitary "'tumor"
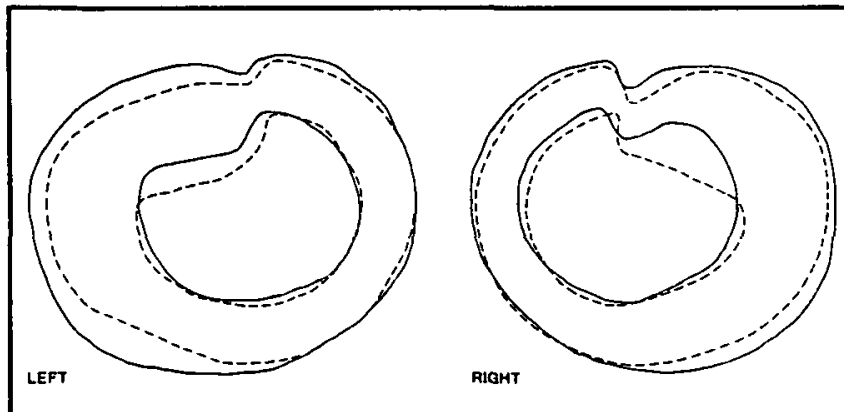

Figure 2 - Visual field studies pre(---) and post( showing improvement. levodopa, decreased cortisol with impaired metapyrone testing indicative of ACTH deficiency, and decreased gonadal function secondary to pituitary insufficiency. Thus even a setting of global pituitary insufficiency can be found in primary hypothyroidism.

Although the patient had no visual complaints, he had impairment in visual fields as described by others. ${ }^{3.5 .8 .9 .11}$ These improved after only 6 weeks of treatment (Figure 2), similar to the changes reported by Yamamoto et al. ${ }^{5}$ Deterioration of the visual field defect during thyroxine replacement therapy has been observed in three patients with visual symptoms. ${ }^{5,11}$ This has been postulated to be due to a disparate rate of inhibition of TSH synthesis and release. ${ }^{5}$ Thus careful follow-up studies of 
vision should be carried out in these patients. Replacement therapy with thyroxine has been associated with pseudotumor cerebri developing in patients with juvenile hypothyroidism. ${ }^{12}$ In this report CT scanning at the time of diagnosis showed the pituitary to be enlarged with suprasellar extension. Following treatment bilateral papilledema developed with headaches and repeat CT showed an empty sella in conjunction with small ventricles and no obstruction. ${ }^{12}$

End organ failure of other endocrine glands may result in pituitary hyperplasia. Nishi et $\mathrm{al}^{7}$ also studied three children with Turner's syndrome and found pituitary enlargement in two and an empty sella in one. It has also been reported in Kleinfelter's, ${ }^{13}$ Addison's disease and congenital adrenal hyperplasia. ${ }^{14}$ Nevertheless, these are rare entities and the importance of recognizing them is illustrated by our case.

In summary, we have described a 12 -year-old boy who presented with growth delay. Although hypothyroidism was recognized, it was initially thought to be secondary to a pituitary mass lesion. The finding of an elevated TSH allowed the correct diagnosis of primary hypothyroidism (Hashimotos's thyroiditis) and medical treatment resulted in rapid resolution of his large suprasellar pituitary "tumor".

\section{ACKNOWLEDGEMENTS}

We wish to thank Dr. H.B. Armstrong for his initial referral.

\section{REFERENCES}

1. Niepce B. Traite du Goitre et du Cretinisme. Baillieri JB, ed. Paris, 1851.

2. Tur-kaspa $R$, Horne $T$, Landau $H$, et al. Pituitary enlargement secondary to hypothyroidism associated with sublingual thyroid gland. Isr J Med Sci 1979; 15: 772-774.
3. Samaan NA, Osborne BM, Mackay B, et al. Endocrine and morphologic studies of pituitary adenomas secondary to primary hypothyroidism. J Clin Endocrinol Metab 1977; 45: 903-911.

4. Khalil A, Kovacs K, Sima AAF, et al. Pituitary thyrotroph hyperplasia mimicking prolactin - secreting adenoma. J Endocrinol Invest 1984; 7: 399-404.

5. Yamamoto K, Saito K, Takaji T, et al. Visual field defects and pituitary enlargement in primary hypothyroidism. J Clin Endocrinol Metab 1983; 57: 283-287.

6. Scheithauer BW, Kovac K, Randall RV, et al. Pituitary gland in hypothyroidism. Arch Pathol Lab Med 1985; 109: 499-504.

7. Nishi Y, Sakano T, Hyodo S, et al. Pituitary abnormalities detected by high resolution computed tomography with thin slices in primary hypothyroidism and Turner syndrome. Eur J Pediatr 1984; 142: 25-28.

8. Vagenakis AG, Dole K, Braverman LE. Pituitary enlargement, pituitary failure and primary hypothyroidism. Ann Intern Med 1976; 85: 195-198.

9. Lecky BRF, Williams TDM, Lightman SL, et al. Myxaedema presenting with chiasmal compression: Resolution after thyroxine replacement. Lancet 1987; I: 1347-1350.

10. Suter SN, Kaplan SL, Ankert ML, et al. Plasma prolactin and thyrotropin and the response to thyrotropin-releasing factor in children with primary and hypothalamic hypothyroidism. J Clin Endocrinol Metab 1978; 47: 1015-1020.

11. Stockigt JR, Essex WB, West RH, et al. Visual failure during replacement therapy in primary hypothyroidism with pituitary enlargement. J Clin Endocrinol Metab 1976; 43: 1094-1100.

12. Van Dop C, Conte FA, Koch TK, et al. Pseudo-tumor cerebri associated with initiation of Levo Thyroxine therapy for juvenile hypothyroidism. N Engl J Med 1983; 308: 1076-1080.

13. Samaan NA, Stepanas AV, Danziger J, et al. Reactive pituitary abnormalities in patients with Klinefelter's and Turner's syndromes. Arch Intern Med 1979; 139: 198-201.

14. Daughaday WH. The Anterior Pituitary. In: Wilson JD and Foster DW, eds. Williams Textbook of Endocrinology. Philadelphia, WB Saunders, 1985, p. 591. 